\title{
Editorial 58
}

\author{
Eric Scerri ${ }^{1}$
}

Published online: 5 March 2018

(C) Springer Science+Business Media B.V., part of Springer Nature 2018

The issue before you marks the beginning of volume 20 and is dedicated to Ray Hefferlin, who passed away not long ago. Ray was a friend and colleague to those of us who work on the periodic table of the elements. I met him some 20 years ago and spoke at Southern Adventist University, his home institution in Tennessee, on a couple occasions. The last time I saw him was at the third international conference on the periodic table held in Cusco, Peru. The fourth article in this issue is an allegory by Ray based loosely on that meeting. ${ }^{1}$ In it he describes the work that he and his colleagues carried out over several decades on molecular periodic tables. I believe I speak for all of us when I say that anybody who ever encountered Ray came away with the impression of the kindest and most dignified person that they had ever met. He will be sorely missed by his family, students, friends and colleagues.

The first article, in this issue displays remarkable scope, in discussing topics such as the reduction of chemistry and the qualities that distinguish chemistry from physics. The article is all the more remarkable because it has been written by Andy Dolino, a graduate student from the Philippines, who gives the impression of somebody who has grappled with these questions for a lifetime.

Next come the highly experienced authors, Peter Nelson and David Johnson from the UK, who take an original look at the valences of the lanthanide series of elements. Among many other fascinating details of f-block chemistry the authors describe an alternative

\footnotetext{
${ }^{1}$ This conference was also the basis for a new book on the periodic table that has just been published. The reference appears in note 2 below.
}

Eric Scerri

scerri@chem.ucla.edu

1 Los Angeles, USA 
conception of valency, as well as the stability of quarter-full and three quarter-full electron shells in addition to the better-known half-full shell effects. ${ }^{2}$

The philosophical aspects of organic chemistry, and stereochemistry in particular, have occasionally been featured in this journal. The third article is by Dumitru Iga from Romania, who explores some interesting differences between the classical Fisher system of sterochemical classification and the more recent approaches following the work of Bijvoet. Iga's analysis is carried out in the context of the linear aldohexoses. The following article, the fourth, is by Ray Hefferlin as mentioned earlier.

The last full-length article is by Alfio Zambon from Argentina who presents a study of triads in the periodic table, a project that he began several years ago in his $\mathrm{PhD}$ thesis. In the course of this study Alfio also discusses the conceptual understanding of the term "element", a question which incidentally will be the focus of a special session at the forthcoming 22nd meeting of the International Society for the Philosophy of Chemistry that will be held in Bristol in the UK. ${ }^{3}$

The issue closes with an opinion piece by Jeffrey Seeman, an organic chemist based in Richmond Virginia, who believes that this journal would benefit from greater degrees of inter-disciplinarity. His comments are directed mainly at an article that was previously published in this journal by Fortin, Lombardi and Martinez Gonzales who will be responding in a future issue of the journal. ${ }^{4}$

\footnotetext{
${ }^{2}$ It is interesting to note, that these authors consider lutetium to be a transition metal element, while taking the lanthanides to consist of the elements from lanthanum to ytterbium inclusive. The previous arguments for considering lutetium and lawrencium as transition metals have tended to be of a physical rather than a chemical nature. The article by Nelson and Johnson appears to support this classification, through an eminently chemical study, although the article does not directly confront this question. One article that does is Scerri, E., Parsons, W.: What Elements Belong in Group 3 of the Periodic Table? in E. Scerri, G. Restrepo (eds.), Mendeleev to Oganesson, Oxford University Press, New York, 2018, pp. 140-151.

${ }^{3}$ https://www.bristol.ac.uk/arts/events/2018/philosophy-of-chemistry-conference.html.

${ }^{4}$ Fortin, S., Lombardi, O., Martínez González, J.C.: Isomerism and decoherence. Found. Chem. 18, 225240 (2016).
} 